\title{
PERSIGUIENDO LOS VIENTOS DEL TIEMPO. JÓVENES, PASADOS COMPUESTOS Y FUTUROS POSIBLES
}

\author{
JOSÉ MACHADO PAIS ${ }^{1}$ \\ CARLES FEIXA PÀMPOLS ${ }^{2}$
}

RESUMEN

Con motivo de la publicación del último libro en castellano de José Machado Pais (Jóvenes y creatividad, 2020), esta conversación con Carles Feixa repasa la trayectoria personal e intelectual de este sociólogo portugués, uno de los referentes en los estudios sobre juventud en Europa y América Latina. Tras evocar la adolescencia y juventud del protagonista en Portugal en la década de 1970 — en torno a la revolución de los claveles rojos de 1974 que acabó con la dictadura salazarista - y repasar sus influencias académicas, el texto se centra en sus aportaciones al estudio de la juventud portuguesa y más tarde europea, así como sus conexiones con investigadores de Brasil y América Latina. En la parte final del artículo expone el origen y contenido del último de sus libros, en el que reúne cinco ensayos fundamentales sobre la creatividad juvenil. Esta búsqueda de «los vientos del tiempo» no supone ningún juicio de valor sobre los jóvenes en general o sobre una generación en particular, sino una apuesta epistemológica por desvelar las caras ocultas de una emergencia social, proyectando hacia el futuro $-\mathrm{o}$ hacia el no futuro- las complejidades del pasado.

PALABRAS ClAVES: JUVENTUD, JUVENOlogía, PORTUGaL, CREATIVIDAD, TIEMPO, FUTURO.

1 Sociólogo del Instituto de Ciências Sociais, Universidade de Lisboa. Correo electrónico: machado.pais@ics.ulisboa.pt

2 Antropólogo de la Universitat Pompeu Fabra, Barcelona. Correo electrónico: carles.feixa@upf.edu 


\title{
A PERSEGUIR OS VENTOS DO TEMPO. OS JOVENS, OS PASSADOS COMPOSTOS E OS FUTUROS POSSÍVEIS
}

\begin{abstract}
RESUMO
Por ocasião da publicação do mais recente livro em espanhol de José Machado Pais (Juventud y creatividad, 2020), esta conversa com Carles Feixa revê a carreira pessoal e intelectual deste sociólogo português, uma das referências em estudos da juventude na Europa e América Latina. Depois de evocar a adolescência e a juventude do protagonista em Portugal na década de 1970 por volta da revolução dos cravos vermelhos de 1974 que encerrou a ditadura salazarista - e revisar suas influências académicas, o texto centra-se nas suas contribuições para o estudo da juventude portuguesa e posteriormente europeia, bem como em suas conexões com pesquisadores do Brasil e da América Latina. $\mathrm{Na}$ parte final do artigo expõe-se a origem e o conteúdo do último de seus livros, o qual reúne cinco ensaios fundamentais sobre a criatividade dos jovens. Esta busca dos «ventos do tempo» não implica nenhum juízo de valor sobre os jovens em geral ou sobre uma geração em particular, mas uma aposta epistemológica no desvendamento dos rostos ocultos de uma emergência social, projetando-se para o futuro — ou para o não futuro- as complexidades do passado.

PALAVRAS-CHAVE: JUVENTUDE, JUVENOLOGIA, PORTUGAL, CRIATIVIDADE, TEMPO, FUTURO.
\end{abstract}

\section{CHASING THE WINDS OF TIME. YOUTH, COMPOUND PASTS AND POSSIBLE FUTURES}

\begin{abstract}
On the occasion of the publication of the latest book in Spanish by José Machado Pais (Youth and creativity, 2020), this conversation with Carles Feixa reviews the personal and intellectual career of this Portuguese sociologist, one of the leaders in youth studies in Europe and Latin America. After evoking the teenage and youth of the protagonist in Portugal in the 1970s - around the red carnation revolution of 1974 that ended the Salazarist dictatorship - and reviewing his academic influences, the text focuses on his contributions to the study of Portuguese and later European youth, as well as their connections with researchers from Brazil and Latin America. In the final part of the article he exposes the origin and content of the last of his books, in which he gathers five fundamental essays on youth creativity. This search for «the winds of time» does not imply any value judgment on young people in general or on a generation in particular, but rather an epistemological bet to reveal the hidden faces of a social emergency, projecting towards the future - or towards the no future - the complexities of the past.

KEY WORDS: YOUTH, JUVENOLOGY, PORTUGAL, CREATIVITY, TIME, FUTURE.
\end{abstract}




\section{INTRODUCCIÓN}

El origen de esta conversación es la publicación del último libro de José Machado Pais: Jóvenes y creatividad. Entre futuros sombrios y tiempos de conquista (Pais, 2020). Se trata de la segunda obra traducida al castellano de uno de los sociólogos portugueses más influyentes, un referente en los estudios culturales y sobre juventud en Europa y América Latina. La primera obra traducida al castellano fue el libro Chollos, chapuzas, changas. Jóvenes, trabajo precario y futuro (Pais, 2007, con prólogo de Feixa). Aquella obra era una monografía sobre las transiciones - e intransiciones - laborales de los jóvenes, a partir de estudios de caso biográficos que predecían los procesos de precarización y cambio en las concepciones del trabajo que se anunciaban, y que se convertirían en hegemónicas tras la crisis financiera de 2008. Este nuevo libro recoge cinco ensayos del autor en torno a otra de sus grandes obsesiones: la creatividad cultural de los jóvenes. La conversación tiene como objetivo rescatar la trayectoria de este autor fundamental, en diálogo con Carles Feixa, con quien lo une una larga amistad. De algún modo, ambos autores han seguido trayectorias paralelas. Aunque este diálogo lo han llevado a cabo muchas veces en persona - en Lisboa, Lleida, Barcelona, Madrid, Valencia, Brasil, Argentina y otros lugares del mundo-, en este caso ha tenido lugar a través del ciberespacio, en parte durante el confinamiento por el coronavirus ${ }^{3}$.

\section{El FAdo de CARMencita}

-CARles FeiXa PÀMPols (CFP): ¡Olá José! Creo recordar que entramos en contacto a fines de los años 90, a través de un colega tuyo del Instituto de Ciências Sociais de la Universidad de Lisboa, Manuel Villaverde Cabral, a quien había conocido en un encuentro en París organizado por nuestra común amiga Lynne Chishom, entonces presidenta del Research Comitee 34 «Sociology of Youth» de ISA y tristemente desaparecida. Cuando me escuchó hablar de las tribus urbanas en España en la época de la transición, me habló de un sociólogo portugués que había investigado lo mismo en la misma época en Portugal. Te escribí y me enviaste tu libro Culturas Juvenis (1993) — desde

${ }^{3}$ Este artículo es una versión ampliada y revisada del prólogo del libro Jóvenes y creatividad (Feixa, en Pais, 2020). Se basa en una conversación mantenida a través de internet en los primeros meses de 2020. Está previsto que el texto aparezca simultáneamente en dos revistas, una chilena (Última Década) y otra portuguesa (Todas as Artes). 
entonces no has parado de enviarme casi todos tus nuevos libros, que religiosamente publicas una vez por año, y que ocupan un entero estante en mi biblioteca- Enseguida me di cuenta de una curiosa coincidencia: tu libro se publicó el mismo año y trataba los mismos temas de mi primer libro importante — La joventut com a metàfora (Feixa, 1993) - y Gerações e valores na sociedade portuguesa se publicó cinco años después (Pais, 1998), coincidiendo con mi libro De jóvenes, bandas y tribus (Feixa, 1998). Ambos estábamos influidos por la escuela de Birmingham, pero no aplicábamos mecánicamente los cultural studies, sino que los adaptábamos al contexto histórico y cultural de Portugal y Cataluña. Además, los dos empezamos a investigar a los jóvenes en una coyuntura histórica particular: las postdictaduras ibéricas en los años 70: Portugal (1973) y España (1975). Para empezar, ¿podrías explicarme tus orígenes familiares y cómo viviste tu adolescencia y juventud en el Portugal de la transición democrática?

—JosÉ Machado PAIS (JMP): Mi familia tiene orígenes rurales. Mi abuelo paterno era el supervisor de un vizconde, el abuelo materno tenía una venta y un establecimiento para la producción y venta de herrajes. Además, eran pequeños terratenientes rurales. Mi padre hizo su servicio militar en Lisboa. Un día volvió a sus orígenes y, en una noche de luna llena, acompañado por un guitarrista, dio una serenata a la puerta de mis abuelos maternos. Sus cinco hijas se asomaron a la ventana, sin saber cuál era la que pretendía. Hasta que mi padre cantó un conocido fado: el fado de Carmencita, «la gitana más bella que un sueño, que una visión». Se enamoraron, se casaron, Carmencita vino a Lisboa y once meses después nací yo. Mi certificado de nacimiento podría indicar que también soy hijo del fado. Por casualidad o no, el primer libro que publiqué fue sobre la bohemia lisboeta de antaño, donde desde mediados del siglo XIX el fado comenzó a marcar una presencia muy fuerte en las tabernas frecuentadas por prostitutas (Pais, 1985). Nunca canté fado, pero sí me uní a algunos grupos musicales y, como el fado callejero, descubrí el gusto de deambular por el mundo. De joven usaba el ferrocarril. Era más barato.

El proceso de transición democrática acompañó mi transición a la edad adulta. A los 15 años comencé a cuestionar la dictadura de Salazar debido a un trauma amoroso. Estábamos con mi enamorada en un banco del jardín, cogidos de la mano. Simplemente cogidos de la mano. En esto, un policía se acercó, de malos modos, maldiciéndonos con sus manos levantadas. Solo muchos años después descubrí la existencia de multas severas contra supuestas manos perversas que violaban la moral pública. Las multas evolucionaban en una 
escala de ofensas morales que, con razón, comenzaban por la mano y evolucionaban así: mano sobre mano; eso en la mano; eso en eso; detrás de eso y con la lengua en eso, el más penalizado de todos los ataques indecentes. ¡Créeme, Carles! Solo estábamos con las manos entrelazadas. Un simple gesto de cariño. Lejos de mí, la intención o la tentación de comenzar una carrera potencial como delincuente moral en un banco de jardín. Ya estudiante universitario, me gradué en Economía, estaba consolidando una conciencia política de oposición a un régimen que movilizó a sus jóvenes contra una guerra colonial irracional, de la que escapé por poco. Fue con emoción natural que experimenté la revolución de los claveles el 25 de abril de 1974. Con el establecimiento de la democracia, descubrí que, como dijo Paulo Freire, liberación no es una palabra hueca o mítica. Es una práctica orientadora para la transformación del mundo.

-CFP: ¿Cómo pasaste de joven a juvenólogo? Es decir: ¿cómo te hiciste sociólogo de la juventud?

-JMP: Las experiencias juveniles fueron decisivas. Cuando tenía 17 o 18 años tocaba en una banda de rock, los Song's Boys. De vez en cuando animábamos bailes de entidades recreativas. Allí tocábamos música más romántica, propicia para parejas. Yo no quitaba los ojos de la pista de baile. El escenario era la ventana discreta de mis registros visuales. Sin saber cómo, el joven que era yo estaba creando una sensibilidad sociológica para capturar lo social. Una situación similar ocurrió con Pierre Bourdieu. Tenía orígenes rurales, nació en la región de los Pirineos atlánticos, y de joven asistió a bailes rurales. Su libro sobre el baile de los solteros, aunque publicado a principios del presente siglo (Bourdieu, 2002), recoge un largo artículo que apareció en 1962 en la revista Études Rurales, como resultado de sus observaciones juveniles.

Entonces, con la guitarra eléctrica en mi hombro y los ojos bailando alrededor de las salas de baile, observé los rituales de aproximación, las estrategias de seducción, las formas y enfoques corporales, los intercambios de miradas, en resumen, la magia de las interacciones sociales y sus simbolismos. Hice observación participante sin saberlo. O más bien, observación remota. Fue esta mirada al mundo del que formé parte lo que dio luz al juvenólogo que soy hoy, lo que me llevó a abrazar el mundo de las ciencias sociales. Por casualidad o no, uno de los primeros libros que publiqué fue sobre rituales de galantería en los círculos burgueses del siglo XIX (Pais, 1986). El interaccionismo simbólico era el marco teórico de referencia, pero las observaciones en el salón de baile agudizaron mi imaginación sociológica. Años más tarde, en Culturas Juvenis 
(Pais, 1993), volvería a interesarme por las citas de los jóvenes, sin olvidar los bailes de presentación en sociedad. La experiencia de la paternidad también fue un incentivo para pensar en los jóvenes a una escala más amplia. Un día, mi hija, de unos 12 años, que acababa de llegar de la escuela, me mostró una misteriosa hoja de papel, bien doblada, a cuyo acertijo me arrastró a su debido tiempo. Preocupada, ella quería mi consejo. Sabiendo que estaba investigando a los jóvenes suponía que debería tener una respuesta. Desplegué ansiosamente la hoja de papel con una tranquilidad mal disimulada. Era una carta para tener suerte en el amor. Con ese fin, tendría que dormir esa noche con la carta debajo de la almohada y escribir, en el pie izquierdo el nombre del chico que más quería para ser su novio. Y luego tendría que escribir seis cartas idénticas y dárselas a otros colegas. De lo contrario, sufriría seis angustias. «Papá, ¿qué hago?», me preguntó. Le dije que no se preocupara, que era un juego de adolescentes. No me convenció la respuesta. Y a ella, mucho menos. Tiempo después terminé escribiendo un libro sobre afectos y sexualidades juveniles (Pais, 2012). Quería saber más sobre la intimidad de los jóvenes. Interpretar el mundo es entregarse al mundo que se nos da. Entonces me convertí en sociólogo y en juvenólogo.

\section{GAFAS ESPEJADAS}

-CFP: En 1998 organicé el primer Fòrum d'Estudis sobre la Joventut en la Universidad de Lleida, junto con otro común amigo, Joan Ramon Saura, entonces delegado de juventud de la Generalitat, y no dudamos en invitarte para hablar de la revolución de los claveles rojos, que tanta influencia tuvo en España. Recuerdo una conferencia espléndida en un aula magna llena de estudiantes, posteriormente publicada como artículo en varios libros editados por mí (Pais, 2000a; 2002). ¿Lo recuerdas?

-JMP: ¡Sí, por supuesto! Jugaste un papel clave en el mapeo de los movimientos juveniles en la península ibérica y América Latina, al invitar a varios colegas a abordar el tema en dos publicaciones importantes (Feixa, 2002a; 2002b). Respondí a tu desafío y en esa reunión hablé de la revolución de los claveles rojos y la contribución que hicieron muchos jóvenes portugueses para hacerla posible. Lo que quedó en la historia fue el papel determinante, y de hecho innegable, de los capitanes de abril a medida que avanzaban con valentía para derrocar al régimen. Sin embargo, aunque no siempre es visible o valorado, la contribución de los jóvenes fue notable. La crisis académica que 
experimentó la universidad portuguesa en 1969 fue el primer gran enfrentamiento de los jóvenes con el régimen. Uno de los momentos de gran tensión política ocurrió en un partido de fútbol en Lisboa. Fue en la final de la copa portuguesa, cuando el Benfica se enfrentó al Académica, un equipo de la Universidad de Coimbra, formado exclusivamente por estudiantes. La universidad estaba de luto por la represión policial contra los estudiantes. Cuando los equipos entraron en el campo, los jugadores del Académica aparecieron con sus capas negras de luto. El estadio estaba lleno, pero los presidentes del Gobierno y la República no aparecieron, ni la televisión oficial transmitió el partido. Se temía la oposición al régimen. Y apareció en el intermedio con carteles en la mano que decían «Mejor educación, menos policía», «Universidad libre», «Democratización de la educación», etc. El juego se prolongó con tiempo extra, el Benfica ganó 2-1, pero muchos aficionados del Benfica lamentaron que el Académica no hubiera ganado la copa.

La guerra colonial en África también movilizó a muchos jóvenes a protestar. En la semana anterior al 1 de mayo, por la noche, los jóvenes pintaron las paredes de Lisboa con inscripciones contra el régimen: «Ningún soldado más hacia África», «Democracia ya», «Abajo el fascismo», «Fin de la guerra colonial», «No somos carne de cañón»... Los capitanes de abril sabían que los días antes de cada 1 de mayo, la policía política vigilaba a los estudiantes. Luego, en 1974, una semana antes del 1 de mayo, decidieron seguir adelante con la revolución. Los jóvenes grafiteros, además de escribir mensajes de revuelta contra el régimen en las paredes, hicieron que la revolución fuera exitosa distrayendo a la policía.

-CFP: En el año 2000 coincidimos en Lisboa en la cumbre europea donde se presentó el White Book on Youth. Tu pronunciaste la conferencia inaugural del evento. ¿Cómo valoras las políticas de juventud a nivel europeo y el papel de los investigadores en su diseño?

-JMP: Recuerdo perfectamente ese evento, celebrado en el Parque das Nações, a orillas del Tajo. Había participado en Bruselas en reuniones preparatorias para el Libro blanco y me invitaron a Lisboa para hablar sobre el futuro de los jóvenes europeos. La reunión juntó a investigadores y formuladores de políticas y el objetivo era promover un diálogo entre ellos, con miras precisamente a la contribución de los investigadores en el diseño de políticas de juventud. En la víspera del evento fui al lugar donde tendría lugar para asistir a un concierto de Oasis. Cuando me encontré con un grupo de jóvenes cyberpunk, estuve pensando en el libro de Bruce Sterling, 
Mirrorshades, una antología dedicada a Mozart y a sus lentes espejados. Metafóricamente, pensé que el futuro de los jóvenes se podía mirar con lentes similares. Quizás estas lentes permitirían reflejar imágenes de significados múltiples y camuflados de las culturas juveniles, o imágenes desconcertadas de las cuales también están hechos los futuros de muchos jóvenes. Hay un punto incuestionable. Los formuladores de políticas colocan el futuro en la ecuación de sus políticas de acción para tomar las mejores decisiones. Es por eso que atraen a los investigadores. Pero eso crea un gran problema para ellos. No pueden poner el futuro en una bandeja y decirles: aquí tienes el futuro, bien sazonado, listo para ser consumido. Sería un error, además viciado por una contradicción. Buscar conocer el futuro es asumir que es conocible, es decir, que ya está determinado. Pero el futuro no está determinado, es una construcción. Aún más el futuro de aquellos que se dice que son el futuro. Es decir, los jóvenes. Como Paulo Freire nos enseñó, la inexorabilidad del futuro es la negación de la historia. Por lo tanto, el futuro debe ser cuestionado en lugar de ser delimitado.

En el presente libro, lo que me propongo es precisamente un cuestionamiento del futuro que nos permite imaginarlo. De esa forma hacemos presente el futuro. ¿Y cómo podemos imaginar el futuro? En la lógica de los sistemas que se autoconstruyen, es decir, reflexivamente. Las políticas de juventud a nivel europeo no han sido insensibles a este problema. Es por eso que han buscado conexiones entre los responsables políticos, los investigadores y los representantes de los jóvenes. Las políticas de intervención pueden ser erróneas si no están ancladas en estudios rigurosos de la realidad. Sin embargo, por otro lado, es necesario tener en cuenta las expectativas que los jóvenes construyen con respecto al futuro y los obstáculos persistentes para su realización.

\section{LÍNEAS FRAGMENTADAS}

-CFP: En 2007 se publicó tu primer libro en castellano, Chollos, chapuzas, changas (Pais, 2007), feliz traducción de Ganchos, tachos e biscates (Pais, 2001), y tuve el honor de escribir el prólogo. El tema del libro era el trabajo precario de los jóvenes y el modelo de «juventud yo-yo», que cito profusamente en mi libro De la Generación@ a la \#Generación (Feixa, 2014). ¿Cómo ha cambiado el panorama del trabajo juvenil después de la crisis de 2009 ? 
-JMP: Hoy el trabajo ha perdido su relevancia como núcleo central para socializar y estructurar el curso de la vida de los jóvenes. En el modelo laboral fordista, el ciclo de vida se estructuraba en torno al trabajo: la preparación para el trabajo, a través de la escolarización, ocurría en la juventud; el ejercicio de una actividad profesional fue un marcador de la vida adulta; el abandono de la vida activa surgió en la vejez. El trabajo normalizó las fases de la vida, secuenciadas linealmente. Todo este panorama se ha transformado. En la senda del antropólogo Tim Ingol (2015) y su breve historia de las líneas, podríamos decir que la línea recta, un ícono de la modernidad, dio paso a líneas rizomáticas fragmentadas, bifurcadas. Es por eso que los jóvenes, cuando se enfrentan con el mundo del trabajo, son artistas de la recomposición creativa, del reencantamiento de lo desechable, de las conexiones rizomáticas, de la creatividad fragmentaria. Recurren a estrategias de scratch, oblicuas, la alquimia de la interconectividad, temas que desarrollo en el cuarto capítulo de este libro. El concepto tradicional de trabajo en sí mismo es cuestionable. En su poema «Menino do Mato», el poeta brasileño Manoel de Barros se refirió a las palabras desgastadas por su uso habitual. El trabajo es una de esas palabras estampadas por costumbre. Las nuevas culturas del trabajo han vuelto a resignificar el concepto al conectarlo con un nuevo espíritu creativo, internalizado por amplias capas juveniles.

Es cierto que en el panorama del trabajo juvenil persisten las vicisitudes asociadas con las desigualdades y exclusiones sociales. De hecho, el concepto de resiliencia está interviniendo cada vez más en las reflexiones teóricas sobre los dilemas de la sociedad actual, incluido el desempleo juvenil. Sin embargo, a los precarios tradicionales por exclusión ahora se unen los precarios por opción. En el primer caso, la supervivencia solo es posible a través de trabajos ocasionales y mal pagados, cuando los hay. En el segundo caso, los caminos profesionales dan paso a la intermitencia y la precariedad que se elige como una forma de vida. La movilidad profesional corresponde a una elección biográfica que no es exclusivamente de naturaleza profesional. Estudios recientes muestran que más del $60 \%$ de los profesionales de la generación millennial tienen una tasa de rotación significativa en el mundo de los negocios, habiendo experimentado, en promedio, más de cuatro trabajos hasta que cumplen alrededor de 30 años. Las empresas están comenzando a adoptar estrategias para retener a estos jóvenes. En este caso están los llamados trendsetters, jóvenes que, debido a su creatividad, lanzan nuevas tendencias en el campo de la moda, las artes, el diseño o el marketing, todos ellos muy conectados con la cultura digital. El libro relevante que publicaste sobre la juventud en la era 
digital (Feixa, 2014), al acentuar el acceso generalizado de los jóvenes a las tecnologías de la información y la comunicación, es una clara evidencia de los cambios incuestionables que se han producido en la sociedad contemporánea, que terminan reflejándose en el mundo de trabajo juvenil

-CFP: En 2009 tuve ocasión de invitarte a Buenos Aires a un foro de revistas de juventud, en el que coincidimos con otros investigadores latinoamericanos como José Antonio Pérez-Islas. ¿Cuál ha sido la recepción de tu obra en Iberoamérica?

-JMP: Tengo buenos amigos latinoamericanos, José Antonio PérezIslas es uno de ellos. En cuanto a la repercusión de mi trabajo en Iberoamérica, es mucho más expresivo en Brasil. Es natural que esto sea así. La mayoría de mis publicaciones están en portugués. Por otro lado, en mi universidad he recibido docenas de estudiantes de doctorado y profesores visitantes de Brasil. Muy pocos de otros países iberoamericanos. Lo que puedo decir con seguridad es que América Latina tiene un gran impacto en mi trabajo. Recientemente publiqué un artículo sobre la chamarrita, un baile de las islas de las Azores con fuerte presencia en toda la región del Río de la Plata, en América del Sur. Con una fuerte presencia en Rio Grande do Sul y Paraná (Brasil), la chamarrita -o chimarrita, como se conoce en Brasil- se extendió a Uruguay y la costa argentina que limita con Brasil, cubriendo toda la región de Entre Ríos y Corrientes. Entre 1864 y 1870, en la guerra paraguaya contra la Triple Alianza, que involucró a Brasil, Uruguay y Argentina, se convocaron y bailaron cantantes entre ganadores y perdedores de la guerra (País, 2018).

Lo que más valoro en los intercambios que tengo con colegas de Iberoamérica es la riqueza del conocimiento compartido, es la experiencia de la investigación como un regalo. También he aprendido mucho de artesanos, poetas y artistas. Gente del pueblo. Nunca olvidaré la lección que un día me dio un guía infantil de Olinda (Brasil). Me sorprendió por su profundo conocimiento histórico, desproporcionado a su edad aparente. Parecía tener unos diez años. Por curiosidad le pregunté su edad. Él me respondió: dieciséis años. Ante mi asombro, agregó: "¿Sabe, señor? Aquí, en Olinda, apenas envejecemos», lo que justifica las privaciones por las que estaba pasando y que se reflejaron en su fisonomía. Con el guía infantil aprendí que las etapas de la vida son parte de un campo de semántica social y simbólica. Es por eso que existe una variabilidad histórica en las representaciones sociales de las etapas de la vida. El otro día, hablando de los misterios de la vida, un poeta improvisador brasileño confesó: «Solo comparo esta vida / con las curvas de la 
letra S / tiene una punta que sube / hay otra punta que baja / Las curvas que van en el medio / A todos nos barajan». Ahora, cada vez que uso el método biográfico, siempre busco las curvas de la vida que me ayuden a interpretarla. En otra ocasión visité a una ceramista paraguaya, Rosa Brítez, en su casa de arcilla en Itá. Me sorprendió la colección de figuras de arcilla apareadas, que reproducen el acto sexual en muchas posiciones diferentes. Le pregunté de dónde surgió la idea. La respuesta sonriente fue reveladora: «Tengo una experiencia de vida, tengo una tribu de hijos». Con Rosa Brítez, recientemente fallecida, aprendí que para descifrar los enigmas de la vida tenemos que abrir la caja fuerte de un tesoro de conocimiento. Contiene experiencias de la vida con todos sus misterios y significados. El tesoro es tanto más valioso cuanto más rica es la experiencia de la vida, es decir, cuanto más se prolonga el paso del tiempo en nosotros.

\section{FUTUROS POSIBLES}

-CFP: En tu último libro en castellano, Jóvenes y creatividad (Pais, 2020), pasas del trabajo a la cultura (aunque también habla de otras formas de ganarse la vida por parte de los jóvenes creadores). ¿Cómo te planteaste el libro y cómo seleccionaste los cinco textos que lo componen?

—JMP: He estado persiguiendo los vientos del tiempo. Hoy en día, los jóvenes lideran nuevas formas de participación social guiadas por un modelo de ecología cultural, donde la cultura misma se toma como una oportunidad para la profesionalización. La idea para el libro surgió cuando un amigo lanzó el desafío en una conferencia organizada por el Centro Reina Sofía para la Adolescencia y la Juventud, en Madrid, a fines de 2017. El tema del Congreso, organizado por la Red de Estudios sobre Juventud y Sociedad, era «Las respuestas juveniles a la crisis». En una mesa redonda con Enrique Gil Calvo, recuerdo haber planteado una pregunta para el debate que problematizaba los posibles futuros en tiempos de crisis. Me apoyé en dos muletas teóricas. La primera fue una idea que Karl Mannheim había desarrollado en un libro publicado en medio de la Segunda Guerra Mundial y traducido al español con un sugerente título: Diagnóstico de nuestro tiempo. En ese libro, el diagnóstico de Mannheim (1946 [1943]) precedió a un pronóstico, lo que sugiere que en tiempos de crisis los jóvenes pueden desempeñar un papel importante en la revitalización de la sociedad. ¿Pero bajo qué condiciones puede ocurrir este protagonismo juvenil? La mayoría de los análisis de la crisis se centran en 
evaluaciones retrospectivas. Sin embargo, sin que tengamos que ignorarlos, creo que debemos valorar la prospectiva. Es decir, en lugar de tomar la crisis como un efecto de factores reversibles, con la expectativa de volver a una supuesta normalidad, es un desafío tentador enfrentar la crisis como un contexto de futuros posibles. ¿Y qué se entiende por futuros posibles? Aquí utilicé otra muleta teórica, tomada de Gabriel Tarde (2007 [1895]) cuando avanzó con el concepto de futuros posibles en sus ensayos de nomadología. Al asociar la duda con la idea de posibilidad, Tarde sostuvo que los futuros posibles dependen estrechamente de una conjunción, el «si». Los «si» son las cortinas que se abren a posibles futuros. Bueno, en este libro mío, es a través de estas cortinas abiertas al futuro que intento revelar los tránsitos de los jóvenes entre oscuros futuros y tiempos de conquista. Esta es, de hecho, la problemática de mi libro, en el que la creatividad juvenil desempeña un papel central.

Entre futuros sombríos y tiempos de conquista, miro hacia atrás con puntos de vista retrospectivos y prospectivos, diagnósticos y pronósticos. Los textos en el libro fueron seleccionados para este propósito. La elección también sopesó la preocupación de contemplar estudios de casos diversificados utilizando diferentes metodologías: encuestas, entrevistas en profundidad, observación participante, análisis de prensa, registros etnográficos y biográficos. En el primer capítulo («La esperanza en generaciones de futuro sombrío») exploro el contexto social de una crisis que genera preocupaciones sobre el futuro, un futuro que parece amenazado por la desesperanza, tanto entre los jóvenes que reclaman el derecho a la indignación como entre los adultos mayores, socialmente desvinculados. También se compararon tensiones y complicidades generacionales, así como expectativas y deseos en relación con un futuro incierto que, en el caso de los jóvenes, culminó en múltiples acciones de protesta. En el segundo capítulo ( «En busca de un Oeste: jóvenes inmigrantes») apunté a jóvenes inmigrantes del Este, que en Europa occidental buscan rehacer la vida y agarrar un futuro imaginado, mucho más plausible que un presente de callejones sin salida. Dos viajes a Rumania me permitieron acompañar y registrar los dilemas de los jóvenes que viven experiencias desiguales entre la tradición y la posmodernidad. En Lisboa entrevisté a algunos jóvenes inmigrantes de Rumania, dando en el libro testimonios de una de las jóvenes entrevistadas, Mihaela, y sus dificultades para adaptarse a una nueva realidad, que no siempre es amigable. En el tercer capítulo («Ciudadanía y participación») problematizo el concepto tradicional de ciudadanía, limitado a los derechos y obligaciones sociales, extendiéndolo a otras formas de ejercicio de la ciudadanía que reclaman no solo los derechos establecidos, sino que 
también luchan por la conquista de nuevos derechos. Se dan ejemplos de esta ciudadanía participativa, de expresión artística y creativa, a partir de diversas manifestaciones de la cultura juvenil. En el cuarto capítulo («Historietas: la oblicuidad en futuros por inventar») acompaño a jóvenes creativos que, en las artes como en la vida, siguen los pasos de la filosofía interseccionista del poeta portugués Fernando Pessoa, en el que las estrategias de la oblicuidad echan raíces. Sobre todo, me concentro en los jóvenes productores de cómics, destacando la alquimia de la interconectividad que transportan del universo de los cómics a la vida real. Finalmente, en el quinto y último capítulo («¿De qué estará hecho el mañana de los jóvenes de hoy?») vuelvo a la idea principal que estuvo en el origen del libro, la de futuros posibles y contingentes. Me pregunto cómo reaccionan los jóvenes ante los tiempos de crisis plagados por una crisis de tiempo y cómo enfrentan la imprevisibilidad del futuro, produciendo un desajuste entre los espacios de experiencia y los horizontes temporales, según la terminología utilizada por Koselleck (1990). En este capítulo, también exploro la conectividad digital, las estrategias de scratch y el conocimiento conectivo, discutiendo su potencial efecto liberador en los desafíos educativos contemporáneos, especialmente en relación con los jóvenes socialmente desfavorecidos.

- CFP: Para acabar, ¿cómo has visto cambiar a la juventud portuguesa e ibérica desde que empezaste a investigarla, hace cuatro décadas?

-JMP: En el análisis de los procesos de cambio social, hay una estrategia metodológica que me atrae. Va en contra de la senda de la investigación tradicional centrada solo en lo predecible. Por esta razón, como sostuvo Collingwood (1946), cuando un investigador descubre lo que sucedió, ya sabe por qué sucedió. Es una reminiscencia de la historia del borracho que, habiendo perdido sus llaves cuando regresó a casa por la noche, insistió en encontrarlas junto a una farola, debido a la iluminación proyectada. Los cambios más sorprendentes y quizás más significativos tienen lugar donde menos se espera. Por ejemplo, en los ritos sociales. En varios pueblos del norte de Portugal hay un rito ancestral, la fiesta de los muchachos, protagonizada por jóvenes solteros. Enmascarados y con cencerros alrededor de su cintura, corren tras cualquier mujer que ven, rodeándola y sacudiéndola, en simulación de actos sexuales. Es un rito de iniciación a la virilidad, donde la identidad masculina se celebra de manera festiva, transgresora y orgiástica. Al anochecer, van al atrio de la iglesia y entonan rimas sarcásticas denunciando el descontento social o el deslizamiento moral por parte de los habitantes del pueblo. En los 
últimos años, los muchachos solteros han quedado sorprendidos. Las chicas huyen en brazos de extraños. Las tiendas dan cuenta de esta amenazante realidad: en la casa del tío Zé, ya huelo a chorizo, su Manuela se va a casar con un suizo; su prima de aspecto elegante, Mitó, tiene el futuro en sus manos, sale con un arquitecto... No solo estamos enfrentando un déficit demográfico, estamos ante todo ante un excedente educativo. El lamento de los muchachos es el resultado de uno de los cambios más importantes en las escuelas en las últimas décadas. ¿Cuál? Acceso a la educación secundaria y superior como una rampa para la movilidad y la emancipación social, especialmente para las mujeres jóvenes. En Europa, las mujeres han suplantado a los hombres para acceder a la universidad, reclamando la igualdad de derechos. De hecho, recientemente, el rito de la fiesta de los muchachos ha sido subvertido. Rechazando el estatuto de perseguida y dominada, las chicas decidieron enmascararse asumiendo el poder de sacudir. Como sugirió Simmel (1969) en sus estudios sobre la cultura femenina, el movimiento feminista no se fortalece solo cuando se reivindican nuevos derechos refutados por el marco de la cultura actual, sino, sobre todo, cuando se proyectan, cuestionan y experimentan subjetivamente formas culturales cualitativamente distintas. Son estas nuevas configuraciones subjetivas las que despiertan capacidades latentes que generan cambios. Esto es lo que sucede en los procesos de subjetivación que, cuando se guían por ideas sociocéntricas, pueden culminar en cambios a una escala social más amplia.

Otro cambio significativo, mucho más visible y debatido, se refiere a la creciente participación de los jóvenes en las culturas digitales. De hecho, los usos digitales están tan extendidos entre los jóvenes, especialmente los más educados, que podemos hablar de una división generacional de naturaleza digital. No es sorprendente que las tecnologías digitales sean utilizadas por los jóvenes como un instrumento de movilización social y política, ya que ofrecen posibilidades de conexión rápida. La conectividad digital hace que los jóvenes de hoy se muevan en un campo de heterotopias. Como sugiero en mi libro, entre una serie de jóvenes contemporáneos surge una heterotopía de oblicuidades, cuya característica distintiva es tomar la conectividad como un trampolín para la creatividad. De hecho, según Foucault (1984), la heterotopía tiene precisamente este poder de aglutinación de múltiples espacios. Pensando en los jóvenes, la heterotopía de las oblicuidades aparece vinculada a lugares de existencia real e imaginada, es decir, a utopías que buscan un terreno de aterrizaje, una especie de enclave para la proyección de un nuevo ethos social, con una fuerte marca generacional. Todo el curso histórico evoluciona de 
acuerdo con la prevalencia de generación o género. Creo que estamos en un momento en que ambas prevalencias coinciden.

\section{LAS CURVAS DEL TIEMPO}

-CFP: Nuestra última coincidencia se ha dado en la Universidad de Manizales, en Colombia. En 2009 me concedieron el doctorado Honoris Causa. En 2018 te lo dieron a ti. También fuimos ponentes invitados en distintas ediciones de la Bienal Latinoamericana de Infancia y Juventudes. Parece que nos vamos persiguiendo, ¿no?

-JMP: En cierto modo, tenemos caminos paralelos y cruzados. Subvierten el principio matemático que sostiene que dos líneas paralelas no se cruzan. De hecho, al interpretar las trayectorias de la vida, lo que importa no es la línea recta sino la oblicua, su enredo, la red de relaciones sociales que estamos construyendo. En la línea de pensamiento del arquitecto brasileño Oscar Niemeyer, diría que no es el ángulo recto lo que me atrae, ni la línea recta, dura e inflexible; lo que me atrae es una curva libre y sensible. Por lo tanto, como Niemeyer (1998), valoro las curvas del tiempo. Es en estas curvas donde surgen los encuentros más inesperados. Las experiencias vitales más llamativas y potencialmente más reflexivas surgen de los giros de la vida, de las curvas de la letra $\mathrm{S}$, a las que metafóricamente se refería el improvisador brasileño. En las curvas del tiempo, estoy feliz de haberte conocido en el camino. Nuestros caminos académicos terminaron entrelazándose de manera dialógica. Cuando en tu libro La imaginación autobiográfica (Feixa, 2018) hablas de la historia de la vida como dialógica, lo que encontraste en común en las biografías de dos revolucionarios catalanes, en el período de la guerra civil española, fue una base ética del compromiso político. Una base ética similar nos une en la forma en que hemos estado desarrollando nuestra producción científica y cómo se la damos a quienes nos leen. La vida es un gerundio, mucho más que un participio; un faciendum, mucho más que un factum; una existencia profundamente anclada a las experiencias de la vida que se enriquecen mutuamente. Los libros que escribimos y leemos son compañeros de nuestras andanzas compartidas.

-CFP: ¿Qué final más poético y profundo! ¡Muito obrigado, querido amigo en gerúndio! ¡Até dentro em breve! 
RECIBIDO: 25 DE MAYO DE 2020

ACEPTADO: 25 DE JUNIO DE 2020

\section{Bibliografía}

Bourdieu, P. (2002). Le bal des célibataires. Crise de la société paysanne en Béarn. Paris: Seuil.

FeIXA, C. (1993). La joventut com a metàfora. Sobre les cultures juvenils. Barcelona: Secretaria General de Joventut. (2014). De la generación@a la \#generación. Barcelona: Ned. (2018). La imaginación autobiográfica. Las historias de vida como herramienta de investigación. Barcelona: Gedisa.

Feixa, C., Costa, C. y Pallarés, J. (Eds.) (2002a). Movimientos juveniles en la Península Ibérica. Grafitis, grifotas, okupas. Barcelona: Ariel.

FeiXA, C., Molina, F. y Alsinet, C. (Eds.) (2002b). Movimientos juveniles en América Latina. Grafitis, grifotas, okupas. Barcelona: Ariel.

Foucault, M. (1984). «Des espaces autres». Conférence au Cercle d'études architecturales, 14 mars 1967. Architecture, Mouvement, Continuité, 5, 46-49.

INGOL, T. (2015). Lineas. Una breve historia. Barcelona: Gedisa.

KoSelleCK, R. (1990). Le futur passé. Contribution à la semantique des temps historiques. Paris: Editions de l'Ecole des Hautes Etudes en Sciences Sociales.

Mannheim, K. (1946 [1943]). Diagnóstico de Nuestro Tiempo. México, D. F.: Fondo de Cultura Económica.

Mendes DE Almeida, M. I. y PAIS, J. M. (2013). Criatividade \& Profissionalizaçao. Jovens, subjectidades e horizontes professionais. Lisboa: Imprensa de Ciências Sociais.

Niemeyer, O. (1998). As curvas do tempo. Memórias. Rio de Janeiro: Revan.

PAIS, J. M. (1985). A Prostituição e a Lisboa Boémia do séc. XIX aos Inícios do séc. XX. Lisboa: Querco. 
(1986). Artes de Amar da Burguesia. A Imagem da mulher e os rituais de galanteria nos meios Burgueses do Séc. XIX em Portugal. Lisboa: Instituto de Ciências Sociais da Universidade de Lisboa.

(1993). Culturas juvenis. Lisboa: Imprensa Nacional Casa da Moeda. (1998). Gerações e valores na sociedade portuguesa. Lisboa: Secretaria de Estado da Juventude. (1999). Traços e riscos de vida. Lisboa: Ambar.

(2000a). Després dels clavells rojos. Moviment i estils juvenils a Portugal. En C. FeIXA y J. R. SAURA (Eds.), Joves entre dos móns. Moviments juvenils a Europa i a l'Amèrica Llatina. II Fòrum d'Estudis sobre la Joventut (pp. 157-178). Barcelona: Secretaria General de Joventut \& UdL.

(2000b). Transitions and youth cultures: forms and performances. International Social Science Journal, 164, 219-232.

(2000c). Culturas juveniles, ocios y estilos de vida. En J. A. Younis (Ed.), Ni diferentes ni indiferentes: los jóvenes en el mundo de hoy (pp. 112-132). Las Palmas: Gobierno de Canarias.

(2001). Ganchos, Tachos e Biscates. Jóvenes, Trabalho e Futuro. Lisboa: Ambar.

(2002). Praxes, graffitis, hip-hop. Movimientos y estilos juveniles en Portugal. En C. FeIXA, C. Costa y J. PAllarés (Eds.), Movimientos juveniles en la Península Ibérica. Grafitis, grifotas, okupas (pp. 13-34). Barcelona: Ariel.

(2006). Nos rastos da solidão. Deambulações sociológicas. Lisboa: Ambar.

(2007). Chollos, chapuzas, changas. Jóvenes, trabajo precario y futuro. Barcelona: Anthropos. (Prólogo de C. Feixa).

(2002). Sociologia da vida quotidiana. Lisboa: Imprensa de Ciências Sociais.

(2010). Lufa-Lufa Quotidiana. Ensaios sobre cidades, cultura e vida urbana. Lisboa: Imprensa de Ciências Sociais.

(2012). Sexualidade e Afectos Juvenis. Lisboa: Imprensa de Ciências Sociais. 
(2018). Chamarrita: uma chama da cultura açoriana na América Gaúcha. Todas as Artes. Revista Luso-Brasileira de Artes e Cultura, $1(2), 11-29$.

(2020). Jóvenes y creatividad. Entre futuros sombríos y tiempos de conquista. Barcelona: Ned.

Pais, J. M. y Blass, L. M. (Coords.). (2004). Tribos Urbanas. Produçao artística e identidades. Lisboa: Imprensa de Ciências Sociais.

Simmel, G. (1969). Cultura Feminina. Lisboa: Galeria Panorama.

TARDE, G. (2007 [1895]). Monadologia e Sociologia. São Paulo: Cosac Nayfy. 